ORIGINAL PAPERS

報 文

(5)
スクリュー押出装置による熔融ポリエチレン

の粘度測定"

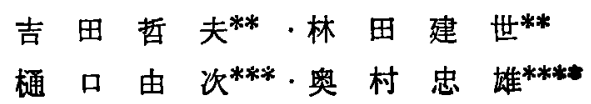

緒寒

熔融プラスチックスの流動特 性を知ることは，このような材 料の押出機構の研究を行らため には不可欠であり，また押出な どの加工を行う場合にも大いに 参考になる。本研究においては 熔融ポリェチレンの流動式が従 来の流れ試験では，いまだ詳に されていない点に鑑み，これを 新しい試みとして小型のスクリ 二一押出装置を用いて求めてみ た。流動式としては，擬塑性に 対する村上の式”がよく適合す ることがわかった。

\section{§1. 実験装植およひ 实験方法}

Fig. 1 は実騒装厧の全体図を 示す。また押出装置本体の断面 图を Fig. 2 に示す。ダイスの 円孔ノズルは内径 $3 \mathrm{~mm}$, 長さ $50 \mathrm{~mm}$ ，バレルの 全長は $410 \mathrm{~mm}$, 内径は $24 \mathrm{~mm}$ で, スクリニー 满の梁さは前方へ向って $4 \mathrm{~mm}$ から $2 \mathrm{~mm}$ まで直 線的に浅くなっている。ダイスとバレルとは滑り 炭合をなし，ダイスはフランジ和よび 3 本のテン ションバー並にナットによって，固くバレルに圧 しつけられており，またバレルとダイスの間から の熔融樹脂の漏洩防止のため，ハッキンを施して ある。補助加熱用ニクロム楾においてては，特にノ ズルの入口および出口付近に插入してある 2 本の 温度㖕が同一示度を示すように，主加熱用ニクロ ム線とは別箇に電流を加减できる。温度計括入用

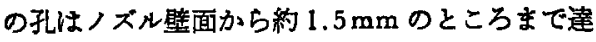
しているから，温度計の示度はほとんど樹脂温度 とみなしてよいと考えられる。またテンションポ

\footnotetext{
* 昭和 31 年 6 月 16 日受理 **陌市立大学理工学部

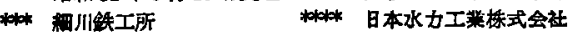

(8)

(8)

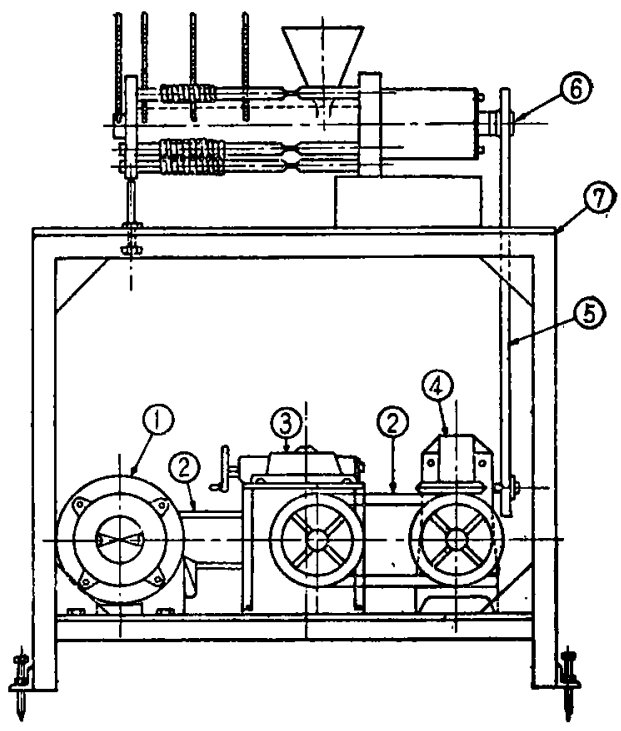

(1) Motor (2) V-Belt (3) Ring Cone (1) Worm \& Wheel (5) Chain (3) Screw Shaft (7) Frame (8) Extruder Proper Fig. 1 General View of Experimental Apparatus

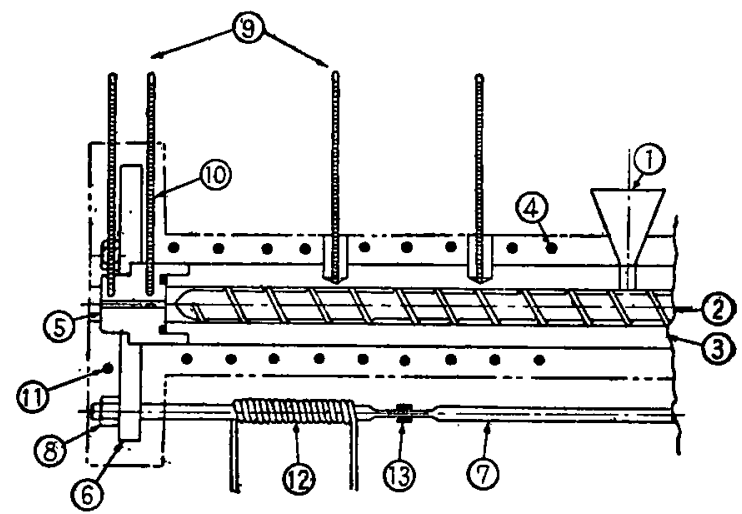

(1) Hopper (2) Screw (8) Barrel (4) Electric Heater (6) Die (b) Flange (1) Tension Bar (a) Nut () Thermometer (10) Asbestos Insulation (11) Supplementary Electric Heater Cooling Water Pipe Strain Gauge

Fig. 2 Sectional Extruder Proper 
一の+ング事の要化を防止するために，これに銅パイフ を巻いて冾却水を通し，その温度を常温付近に保持して いる。

さて、ダイス直前の圧かはダイスよりフランジを経て テンションパーに引張力として加わるから，その歪をこ れ《貼付したストレーンダージまよび抵抗線永計によっ て運転時と停止時との読みの差から湘定すれば，压力は 次式から算出できる。

$$
P=(A E / S) \Sigma \varepsilon
$$

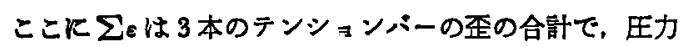
$P$ はダイス直前の圧力と大気圧との圧力恙を意味する。

一方，押出量はストップウオッチおよび天科で秤量し た。スクリュー回転数は 10〜120 r.p.m. の間で無段的に 変化させ, ダイネ温度は $160^{\circ}, 180^{\circ}, 200^{\circ} \mathrm{C}$ の各場合 につき実娩した。

試料は分子量 23000 のペレット状 Eastman 製品を用 いた。

なお本方法による粘度測定の利点として，次の事項が 挙げられる。i）スクリニ一の擋拌による均一加熱がで き，また捏和効果す上げられること。ii）ピストンとシ リンダーに上る押出方式に沶いて起るよ5なピストンの 速度の变化などの影響が避けられること。 荅）速続测 定ができ，試料の交換および供給が容易てあること。

\section{2. 実験结果}

テンションパーの材料（S45C）のヤング象は, フム スラー万能試験機による別简の実験から，E=1.98 $\times 10^{6}$ $\mathrm{Kg} / \mathrm{cm}^{2}$ (室温 $23^{\circ} \mathrm{C}$ ) と求められた。また実物のテンシ ョンバーの両端とナットを付し, 引㲀試験を行い荷重と 抵抗線歪計から求められる昰との関保が計算と実測とで 一致することをあらかじ確かめた。

Fig. 3 は 4 ゲーシ法（倍感度法）によって求めたテン ションバーの歪の合計 $2 \sum \varepsilon$ と押出量 $G$ との実測值の関 係を示す。劝力の非常低低、範囲の測定値は求め難いが 全体の傾向からみて，注とんと擬塑性飞近いと考えられ る。実測点の散乱は，测定誤差で材料の沲動特性は法社 その中間を滑らかな曲線で退移するすのと考元られるか ら，これから実袙で示すような3本の滑らかな押出曲線 がえられる。これから各温度におけるポメチレンの比 重 (カタログから $160^{\circ}, 180^{\circ}, 200^{\circ} \mathrm{C}$ K蜼いてそれそれ $0.784 ０ .775 ， 0.763$ なる值を用いた。なおこの值は後 述与る流動式中の 3 常数 $\eta^{*}, m, n$ の中， $n^{*}$ の值にの 影響し， $m, n$ の值沈影繁しない）を用いて押出重量 $G$ を押出容棈 Q 飞換算し，また（1）式を用いて歪 $2 \sum \varepsilon$ を押出压力 $P$ 飞換算すれば，容易に $P$ 一Q 線が兄られる がこの曲線上の点をある間隔で取ったすのが Fig. 7
に示す各実測点である。

\section{3. 流野式の決定}

従来擬塑性化対する流動式としては Waele-Ost-

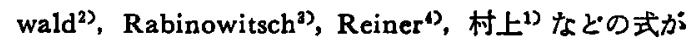
あるが，前 2 者は次の村上の式

$$
-\frac{d v}{d r}=\frac{1}{\eta^{*}} \tau+\frac{m}{\eta^{*}} \tau^{\pi}
$$

に包含される。したがってここでは一層一般的な実験式 と考六られる（2）式を用い，またその 3 常数 $\eta^{*}, m, n$ は桜田, 曽根の方法 ${ }^{5}$ に上って求めてみたが, 後に示す ように計算值と，実測值とが良く一致することがかかっ た。

すなわち（2）式を皘分して流量Qを計算すれば，つ きの諸式がえられる5゙。

$$
\begin{aligned}
& \frac{Q}{R^{3}}=\frac{\pi}{4} \frac{1}{\eta^{*}} \tau_{w}+\frac{m \pi}{n+3} \frac{1}{\eta^{*} \tau_{\omega}{ }^{n}} \\
& \frac{Q}{R^{3}} \frac{1}{\tau_{w}}=\frac{\pi}{4} \frac{1}{\eta^{*}}+\frac{m \pi}{n+3} \frac{1}{\eta^{*} \tau_{\omega}{ }^{n-1}} \\
& \log \left(\frac{Q}{R^{3}}-\frac{\pi}{4 \eta^{*}} \tau_{\omega}\right)=\log \frac{m \pi}{(n+3) \eta^{*}}+n \log \tau_{\omega}
\end{aligned}
$$

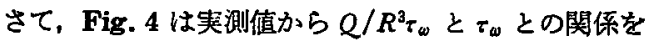
点䊉したるので，曲線を $\tau_{\infty}=0$ まで外挿すれば，(4) 式 から $\tau_{\omega}=0$ に和ける縱座摽は各温度に拈ける $\pi / 4 \eta^{*} の$ 値を与えるので，これからグが算出できる。

Fig. 5 は $\left(Q / R^{3}\right)-\left(\pi \tau_{\omega} / 4 \eta^{*}\right)$ と $\tau_{\omega}$ との実測值を対 数目盛で点緅したもので, 各温度に対し実測点が法とん ぞ一直袙上に並んた。これは（2）式の適合性を示す訳で （5）式により各直線の勾配から各温度に対与るnの值が 求められる。したがってまた $m$ の值も求められる。

Table 1 にはこれらの值を総括してある。

また Fig. 6 は $\eta^{*}, m, n$ の温度による交化を図示した

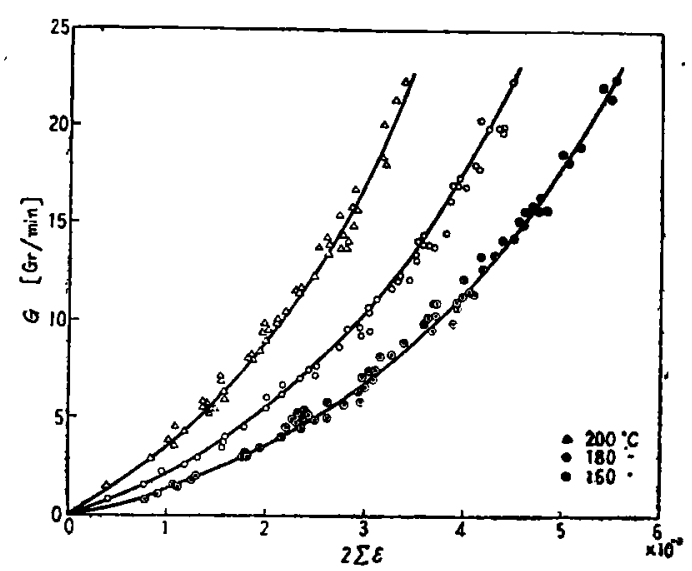

Fig. 3 Plot $G$ vs. 28 . 


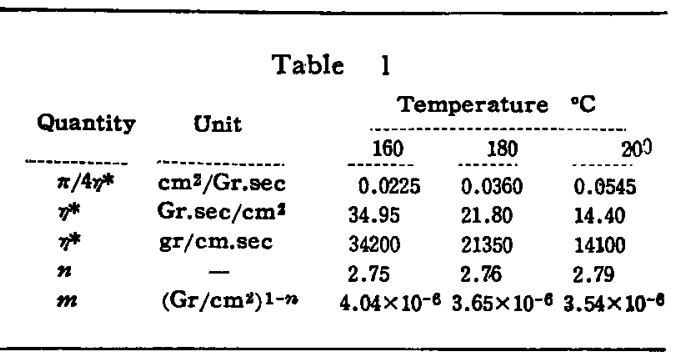

あのである。

なお，この上うにして求めた 3 常数 $\eta^{*}, m$ および の値の妥当性を試すために，これらの值を用い，(3) 式 からPーQの関保を計算して图示すると Fig. 7 の实線で 示すことき曲繶が描かれるが，実測值を示す各点は良く

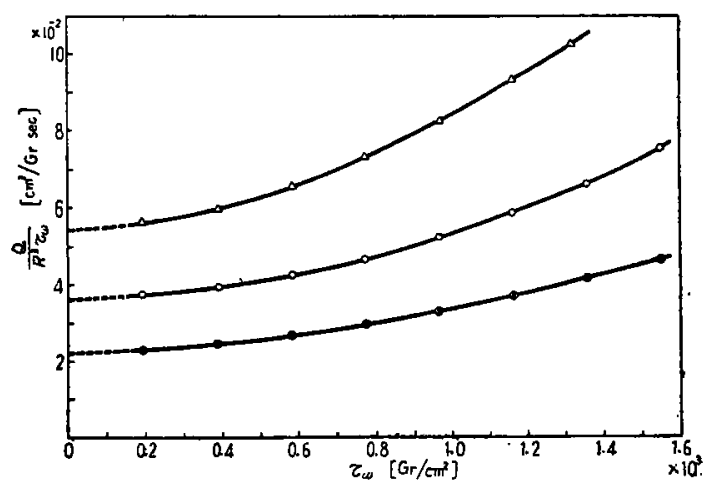

Fig. 4 Plot $Q / R^{3} \tau_{\omega}$ vs. rw

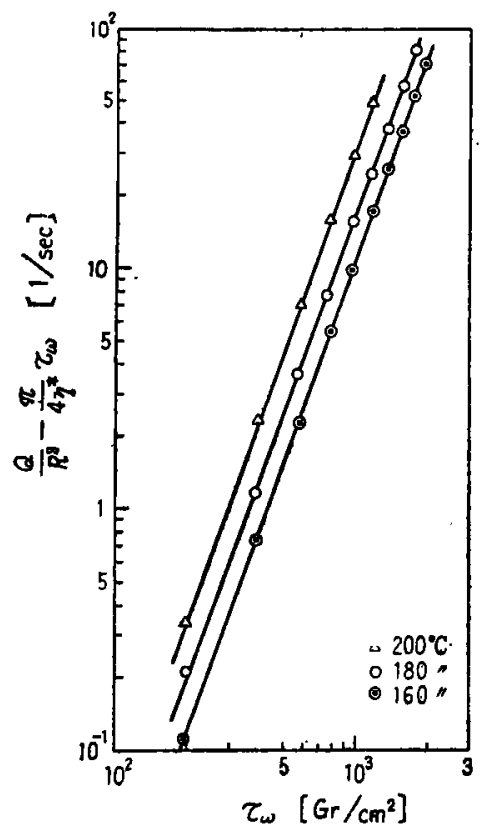

Fig. 5 Plot $Q / R^{s} \sim \pi \tau_{\omega} / 4 \eta^{*}$ v8. $\tau_{\omega}$

\section{計算曲線上に乗ってくる。}

さらに, Fig. 8 は (2) 式を

$$
\eta^{*} D=\tau+m \tau^{n}
$$

と書いたときの $D$ て曲線を描いたるのである。これか 与各常数の値の適用範围愠度 $200^{\circ}, 180^{\circ}, 160^{\circ} \mathrm{C}$ K对 して，それそれ新断応力が $1.4,1.8 ， 2.2 \mathrm{Kg} / \mathrm{cm}^{2}$ まで の範囲といらことになる。

最後に上記温度範围で活性化エネルギー $E_{v}$ を求めて

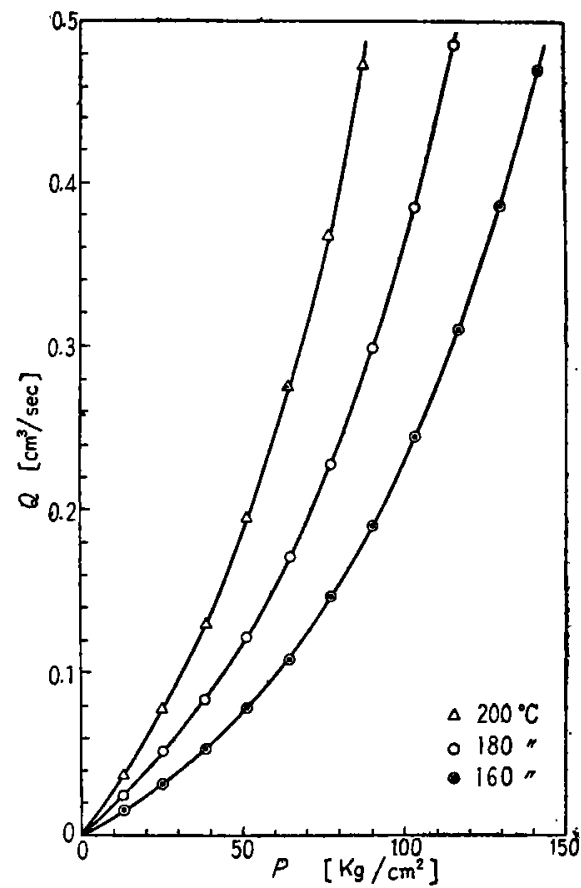

Fig. $7 \quad$ Plot $Q$ vs, $P$ and Calculated Curves
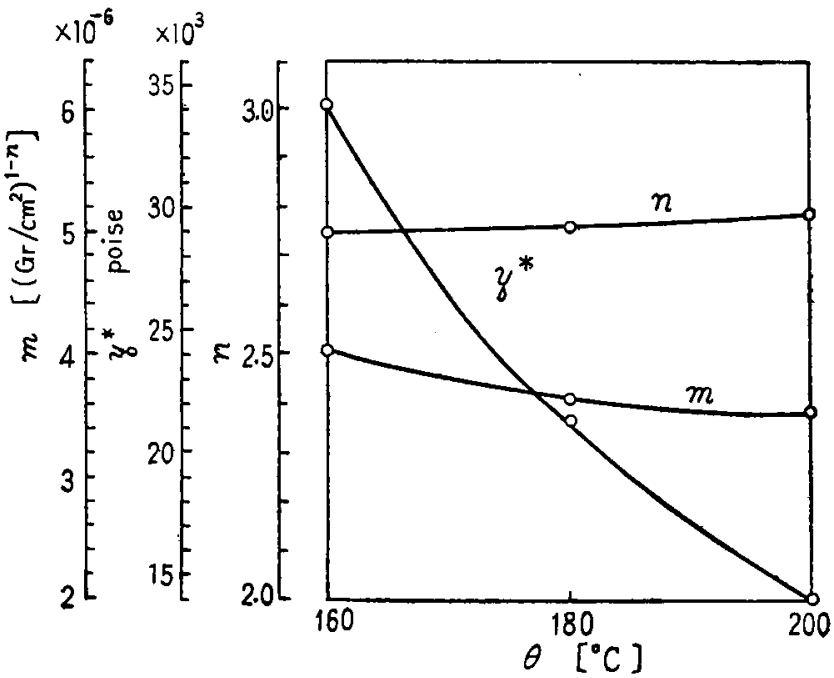

Fig. 6 Change of $x^{*}, m$ and $n$ with Temperature 


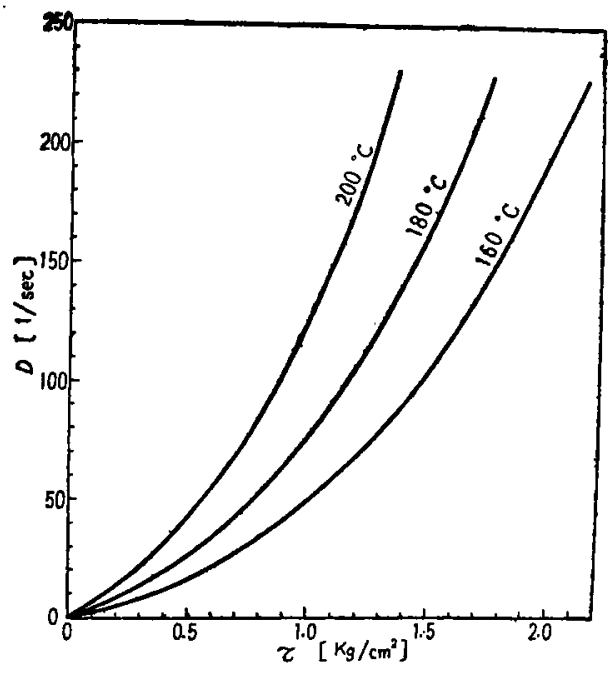

Fig. 8 Consistency Curves

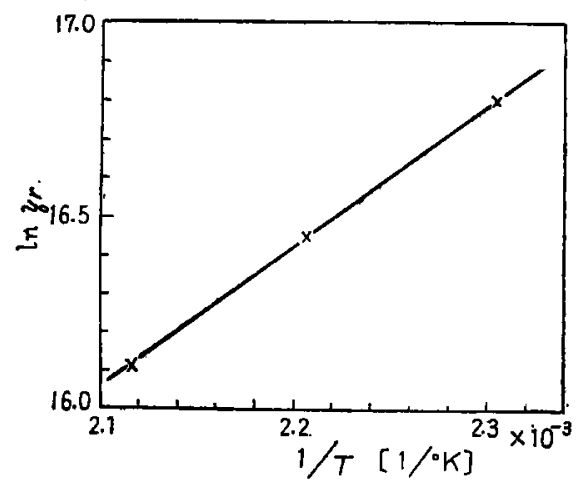

Fig. 9 Plot in $\eta$. vs. $1 / T$

みた。すなわち水の粘性俰数它 $\eta_{w}$ とするとき， $\eta_{r}=\eta * /$ $\eta_{w}$ と扰き， $\ln \eta_{r}$ と $1 / T$ との関係を图示すると，Fig. 9 のことく大体直線となるか，その勾配は $E_{v} / R_{g}=3.63$ $\times 10^{3 \circ} \mathrm{K}$ となるから $R_{q}=1.987 \mathrm{cal} /{ }^{\circ} \mathrm{K} \cdot \mathrm{mol}$ なる值を 用いて $E,=7.21 \mathrm{kcal} / \mathrm{mol}$ と計算された。

\section{結 亭}

新しい試みとしてスクリニー押出装置を用い，分子量 23,000のポりエチレンに対し, 温度 $160^{\circ}$ ないし $200^{\circ} \mathrm{C}$ において, 勏断応力 1.4 ないし $2.2 \mathrm{Kg} / \mathrm{cm}^{2}$ まで適合す る流動特性を求めた。流動式としては，擬塑性に対する $\eta^{*} D=\tau+m \tau^{*}$ が良く適合し，その 3 常数 $\eta^{*}, m$ およひ $n$ を求めた。な打本実験方法は粘度測定法としてす 1 . で述べたような特長を有していると咅兄られる。

附記：本研究に際して有益なこ教示とこ靴維を睗っ た東大工学部、森教授ならびに試料の幹旋をしていただ き，かつ有益なこ助言をいただいた濑水化学工務課長村 上健吉氏に対し深く感謝する。

\section{Nomenelature}

$A$ : Sectional area of tension bar at strain gauge

[cm $\left.{ }^{2}\right]$

$D=-d v / d r:$ Velocity gradient

$E$ : Young's modulus

$\left[\mathrm{Kg} / \mathrm{cm}^{2}\right]$

$E_{v}$ : Energy of activation

[kcal/mol]

$G$ : Rate of flow

[Gr/min]

$m$ : Flow constant

$\left[\left(\mathrm{Gr} / \mathrm{cm}^{2}\right)^{1-n}\right]$

$n:$ Flow constant

$$
[-]
$$

$P$ : Pressure

$Q$ : Rate of flow

$\left[\mathrm{Gr} / \mathrm{cm}^{2}, \mathrm{Kg} / \mathrm{cm}^{2}\right]$

$R$ : Radius of nozzle

$\left[\mathrm{cm}^{3} / \mathrm{sec}\right]$

[cm]

$R_{g}$ : Gas constant [cal $\left./{ }^{\circ} \mathbf{K} \cdot \mathbf{m o l}\right]$

$S$ : Sectional area of barrel inside $\left[\mathrm{cm}^{2}\right]$

$T:$ Absolute temperature

$\varepsilon$ : Strain of tension bar

$\theta:$ Temperature of polyethylene

$\eta^{*}:$ Flow constant $\left[\mathrm{Gr} \cdot \mathrm{sec} / \mathrm{cm}^{2}, \mathrm{gr} / \mathrm{cm} \cdot \mathrm{sec}\right]$ $\eta_{r}=\eta^{*} / \eta_{w}$ : Relative viscosity

$[-]$

$\eta_{w}$ : Coefficient of viscosity of water

$$
\text { [Gr} \left.\cdot \mathrm{sec} / \mathrm{cm}^{2}, \mathrm{gr} / \mathrm{cm} \cdot \mathrm{sec}\right]
$$

$\tau$ : Shearing stress

$\left[\mathrm{Gr} / \mathrm{cm}^{2}, \mathrm{Kg} / \mathrm{cm}^{2}\right]$

$\tau_{\omega}$ : Shearing stress at nozzle wall

$\left[\mathrm{Gr} / \mathrm{cm}^{2}, \mathrm{Kg} / \mathrm{cm}^{2}\right]$

\section{Literature cited}

1) Murakami, K. : Trans. Chem, of High Polymer (Japan), 8, 360 (1952)

2) Ostwald, W. : Koll. Z. 36, 99, 157 (1925); Waele, A. : J. Oil and Colour Chem. Assac., 6, 33 (1923)

3) Rabinowitsch, B. : Z. Phys. Chem., 145, 1 (1929)

4) Reiner, M. : Twelve Lectures on Theoretical Rheology, p. 133 (1948)

5) Sakurada \& Sone : Trans. Chem, of High Polymar (Japan), 10, 202 (1953) 


\title{
Studies on the Extrusion of Molten Plastics (1 st Report) - Viscosity Measurement of Polyethylene-
}

\author{
T. Yoshida,* K. Hayashida, \\ Y. Higuchi \& T. Okumura
}

To know the flow characteristics of molten plastics is very important for the study and the practice of extrusion of the like materials. In the present research work, the flow characteristics of polyethylene (Eastman, molecular weight $=23000$ ) were obtained for the temperature from $160^{\circ}$ to $200^{\circ} \mathrm{C}$ with a small screw extruding apparatus. The pressure was calculated from the strain of tension bar by means of a strain meter. The rate of flow was also measured. Thus, the correlation between the rate of flow and the pressure was obtained, according to which three flow constants in the rheological equation ${ }^{13}$

$$
-\frac{d v}{d r}=\frac{1}{\eta^{*}} \tau+\frac{m}{\eta^{*}} \tau^{*}
$$

were calculated by the Sakurada-Sone method ${ }^{52}$ as shown in Table 1.

The merits of this method of viscosity measurement with the screw extruding apparatus are as follow:

1. Uniform heating and kneading effect are obtained by the stirring motion of the screw.

2. Continuous measurement is possibte and feed and change of test material are very easy.

3. Change of piston velocity which occurs in the "piston and cylinder" apparatus can be avoided.

* Institute of Polytechnics, Osaka City University

\section{Precoat Filtration}

新しい話ではないが一筆。これは，たた助凧のブレ゙ 一トをした上で目的の原乳の溥過をするとい5たけのこ とではなく, Precoat-cutting filtration とてるいってる

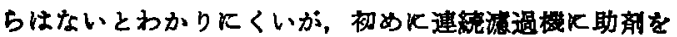
厚くブレニートし，スクレーパーKよるケークの切りと りを完全にするために少しつつ助㶡面をす含めて剀りと ってゆく半連続の方法につけた名称てある。

助剂をつけて源過しても直ぐКベットリと目が塞がれ

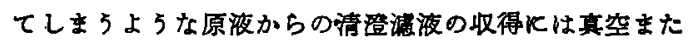
は加压方式として好適であろう。このような萝しにくい

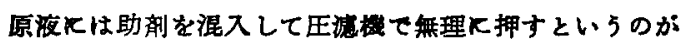
普通の止むをえない対策であったように思 5が，どらし てす自動連続化を完遂したかったのてあろら。

このためにはスクレーバー它しつつ、移動させる必 要がちり，それは microscrew advancing cutting knifeKよる由で,一例によると楖めのブレコートの量は $3^{\prime \prime}$ くらいの厚さ（約 $6 \mathrm{lb} / \mathrm{ft}^{2}$ ) て切りとり速度 0.5 0.0251b/f $\mathrm{ft}^{2} \cdot \mathrm{hr}$ の程度の由であるから， 1 回が 0.5 10 日間で，スクレーバーの送りは 6〜0.3 mm/fr とい5こ そになる。このよらに範围の広いのは，物によってケー
クになるへき固形分が助剤原に浸入したりする堨合すお

りろるためかと思われる。 あまり大を太進步の見られない源過操作の一つの前通 であったといってよいであろらが、大型の場合ならぱス クレーパーの下の源面に助剂詊を連続泩加することによ って，スタレーヘーを動かしたり半連続にしたりする情 性を払わず化すはしないであろらか。また，切削る平 板状のスタレーベーよりる，高速回転のスクリニーの周 辺を伎った方水よく岋あるまいかという気がする。

なお，ついてながら，加区式です真空方式でも，助用 のプレコートをして荤耺する場合に洼来の Blow back のための面倒な構造は必要がないるけである。

Perry, J. H. : "Chem. Engrs. Handb." 3rd. Ed., p 978 9, (1950)

Kirk, R. E. \& Othmer, D. F. : "Ency. of Chem. Tech.", Vol. 6, p 523 4, (1951)

Grace, H. P. : Chem. Eng. Prog., 47, 502 7, (Oct., 1951)

Nickolaus, N. \& Dahlstrom, D. A. : Chem. Eng.Pros., 52, 87 93, (Mar., 1956)

（女献拥聚）北条：本声，20，464，(No. 8，1956）

（传藤敬夫） 